\title{
Effecf of X-Ray Irradiation on Muscle Relaxants
}

\author{
By \\ Kenichi Iwatsuki and Kimio Yokozawa* \\ (岩月 贀一) \\ (横 沢 公 雄) \\ Department of Anesthesiology, Faculty of Medicine, \\ Tohoku University, Sendai, Japan
}

(Received for publication, August 4, 1959)

Several informations ${ }^{1-4)}$ concerning the response of irradiated animals to anesthetic agents have been available, indicating that the action of certain anesthetic agents can be modified by x-ray irradiation. However, no reference is found to the problem whether the action of muscle relaxants may be affected by x-ray irradiation. Because of the extensive utilization of $x$-ray and radio-isotope therapy as well as the widespread application of muscle relaxants in anesthesia, it seems not only interesting but also significant to investigate the effect of x-ray irradiation on the action of muscle relaxants. The results of experimental study from this point of view were presented in this paper.

\section{Methods}

Adult rabbits weighing 2-3 kg. were used for this experiment. After anesthesia was induced with intramuscular nembutal $(25-30 \mathrm{mg} . / \mathrm{kg}$. of body weight), the animals were fixed in a supine position. Twitches of the tibial muscle evoked by the supramaximal electric stimulus were recorded on a smoked paper drum. The electric stimulus was applied at 5 second interval on the innervating nerve. The muscle relaxants tested were succinylcholine chloride (S.G.C.), $d$-tubocurarine chloride (dTc) and gallamine triethiodide (flaxedil), which were administered intravenously. The action of these muscle relaxants was recorded previously as a control, then the animals were irradiated with Shimazu X-Ray Therapy Machine at $180 \mathrm{KVP}$ and $15 \mathrm{ma}(0.5 \mathrm{~mm}$. aluminum and $0.5 \mathrm{~mm}$. copper filter $)$ under the following factors. Within 60 minutes after irradiation the second doses of the muscle relaxants were administered. Enough periods of time (60 minutes in S.C.C. ; 2 hours in flaxedil and 6 hours in. dTc) were elapsed between each administration of the relaxants to avoid a cumulative effect

* Department of Surgery, Faculty of Medicine, Shinshu University. 
TABLE I

Factors of Irradiation in Rabbits

\begin{tabular}{lccc}
\hline $\begin{array}{l}\text { Irradiated } \\
\text { regions }\end{array}$ & $\begin{array}{c}\text { Skin-focus } \\
\text { distance }\end{array}$ & $\begin{array}{c}\text { Irradiated } \\
\text { area }\end{array}$ & $\begin{array}{c}\text { Dose rate } \\
\text { per min. }\end{array}$ \\
\hline Head & $30 \mathrm{~cm}$. & Cicle $(3 \mathrm{~cm}$. radius $)$ & $60 \mathrm{r}$ \\
Whole body & $50 \mathrm{~cm}$. & & $22 \mathrm{r}$ \\
Liver & $30 \mathrm{~cm}$. & $6 \times 6 \mathrm{~cm}$. & $60 \mathrm{r}$ \\
Limb & $30 \mathrm{~cm}$. & $6 \times 6 \mathrm{~cm}$. & $60 \mathrm{r}$
\end{tabular}

or tachyphylaxis due to subsequent doses. Experiments were repeated in 3 animals in each series.

\section{Results}

\section{Succinylcholine chloride (S.C.C.)}

Irradiation of $500 \mathrm{r}$ on the whole body resulted in a definite potentiation and prolongation of the action of S.C.G. (Fig. 1). Irradiation of $250 \mathrm{r}$ still exerted a similar effect, but far less in its degree (Fig. 2). In order to ascertain whether it is due to a local or a general effect of irradiation, the limb used for the experiment was irradiated, when no significant

Fig. 1
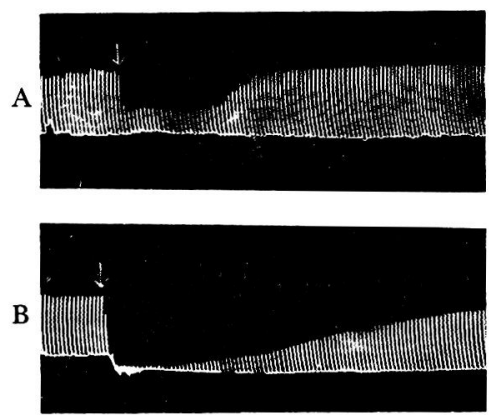

Fig. 2

A

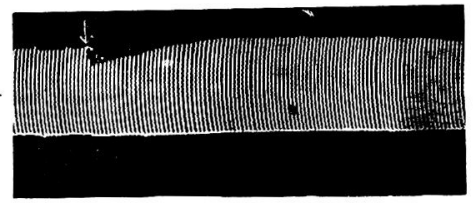

B

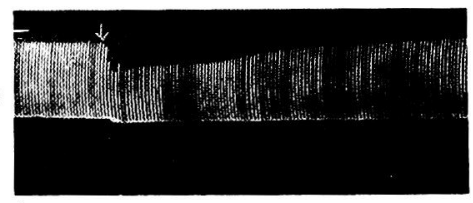

Fig. 1. Effect of whole body irradiation on S.C.C. Rabbit $2.3 \mathrm{~kg}$. S.C.C. $0.14 \mathrm{mg}$. A : Control B : after $500 \mathbf{r}$ irradiation

Fig. 2. Effect of whole body irradiation on S.C.C. Rabbit $2.1 \mathrm{~kg}$. $\quad$ S.C.C. $0.12 \mathrm{mg}$. A : Control B : after $250 \mathbf{r}$ irradiation

changes were observed in the action of S.C.C. even after irradiation of $1000 \mathrm{r}$ (Fig. 3), indicating that a direct effect of irradiation on the limb may not be responsible. Irradiation of $1000 \mathrm{r}$ on the head resulted in a slight potentiation (Fig. 4). The liver can be expected to be influenced by x-ray irradiation, therefore the effect of liver irradiation on the action of S.C.C. 
Fig. 3

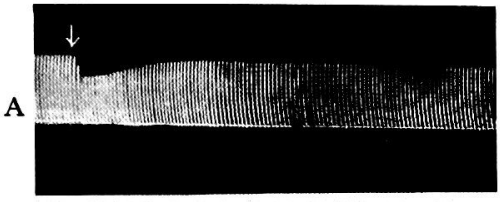

B

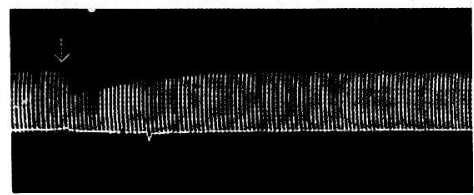

Fig. 4
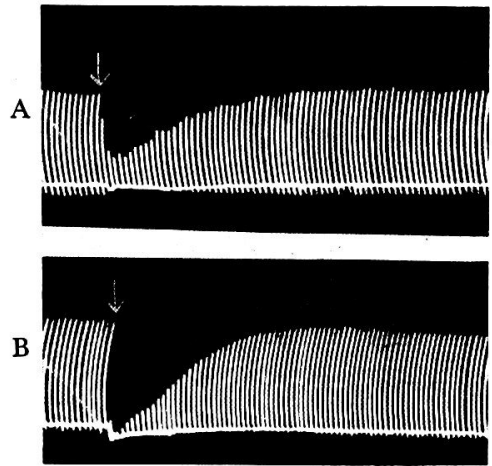

Fig. 3. Effect of limb irradiation on S.C.C.

Rabbit $2.3 \mathrm{~kg}$. S.C.C. $0.12 \mathrm{mg}$.

A : Control B : after $1000 \mathrm{r}$ irradiation

Fig. 4. Effect of head irradiation on S.C.C.

Rabbit $2.5 \mathrm{~kg}$. S.C.C. $0.16 \mathrm{mg}$.

A : Control B : after $1000 \mathrm{r}$ irradiation

was studied. As shown in Fig. 5, the action of S.C.C. was more remarkably potentiated than by whole body irradiation. Such a tendency was seen even after $50 \mathrm{r}$, but negligible after $25 \mathrm{r}$ irradiation. When the animals were protected from $\mathrm{x}$-ray just by covering the region of the liver with a lead plate, even $1000 \mathrm{r}$ irradiation on the whole body exerted almost no effect (Fig. 6). These results suggest that the influence due to liver irradiation may play a great role for the potentiated action of S.C.C. after irradiation.

2. D-tubocurarine chloride (dTc) and Gallamine triethiodide (flaxedil)

Irradiation of $500-1000 \mathrm{r}$ on the whole body or on the liver result in a slight decrease in the action of dTc (Fig. 7 and 8), just contrary to S.C.C. Almost no effect was observed on the action of flaxedil after irradiation of $1000 \mathrm{r}$ on the whole body (Fig. 9).

\section{Discuission}

A few informations ${ }^{1-4}$ ) have been available concerning the effect of $x$-ray irradiation upon the susceptibility of general anesthetic agents, but no reference is found so far to the problem whether the action of muscle relaxants may be influenced by x-ray irradiation. Burdick (1953) ${ }^{1)}$ observed that ether, ethylene, cyclopropane and thiopental increased mortality of rats when anesthesia was given 1-3 hours after irradiation, while nitrous oxide possibly afforded some degree of protection. Wilson (1955) ${ }^{2}$ failed to reveal any significant changes in the 30 day mortality of rats for these anesthetic agents when anesthesia was given 7 days after irradia- 
A 1

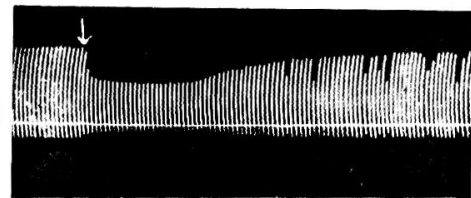

A 2

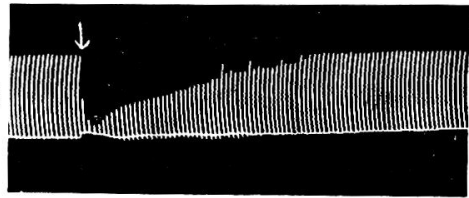

C 1

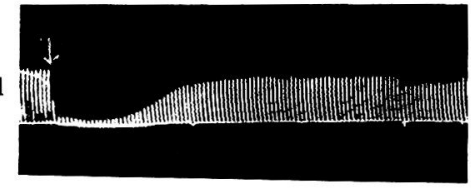

C. 2

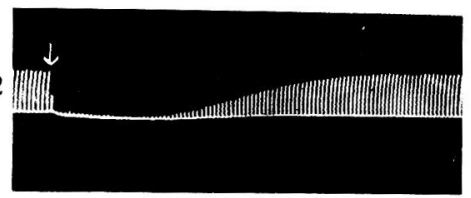

B

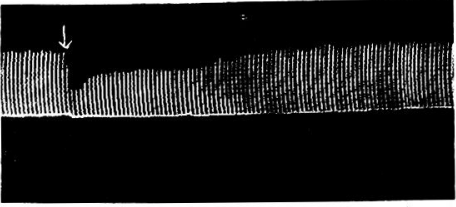

B 2

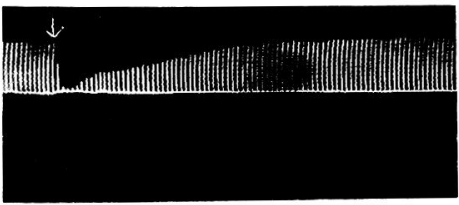

D

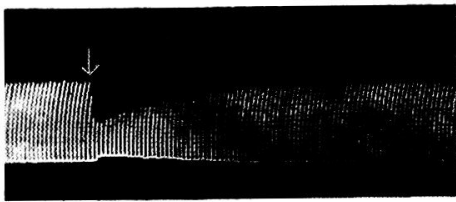

D 2

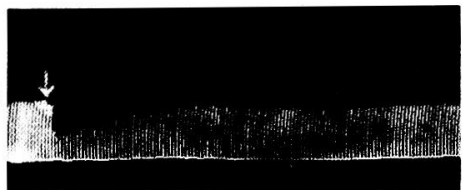

Fig. 5. Effect of liver irradiation on S.C.C.

A : Rabbit $2.3 \mathrm{~kg}$.

A 1 : Control

B : Rabbit $2.5 \mathrm{~kg}$.

B 1: Control

C: Rabbit $2.6 \mathrm{~kg}$.

C 1 : Control

D : Rabbit $2.2 \mathrm{~kg}$.

D 1: Control
S.C.C. $0.14 \mathrm{mg}$.

A 2 : after $500 \mathrm{r}$ irradiation

S.C.C. $0.16 \mathrm{mg}$.

B 2 : after $100 \mathrm{r}$ irradiation

S.C.C. $0.16 \mathrm{mg}$.

C 2 : after $50 \mathrm{r}$ irradiation

S.C.C. $0.12 \mathrm{mg}$.

D 2 : after $25 \mathrm{r}$ irradiation
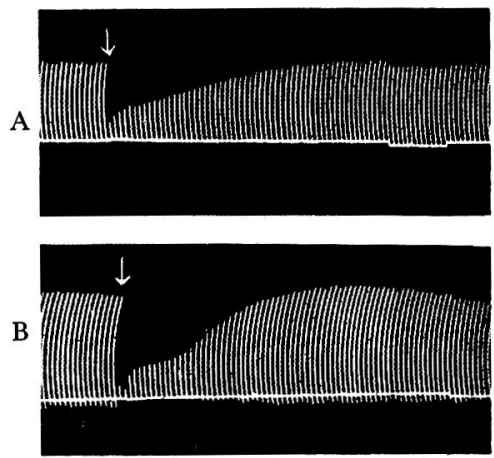

Fig. 6. Effect of whole body irradiation on S.C.C. with liver protection

Rabbit $2.5 \mathrm{~kg}$.

A : Control
S.C.C. $0.16 \mathrm{mg}$.

$\mathrm{B}$ : after $1000 \mathrm{r}$ irradiation 

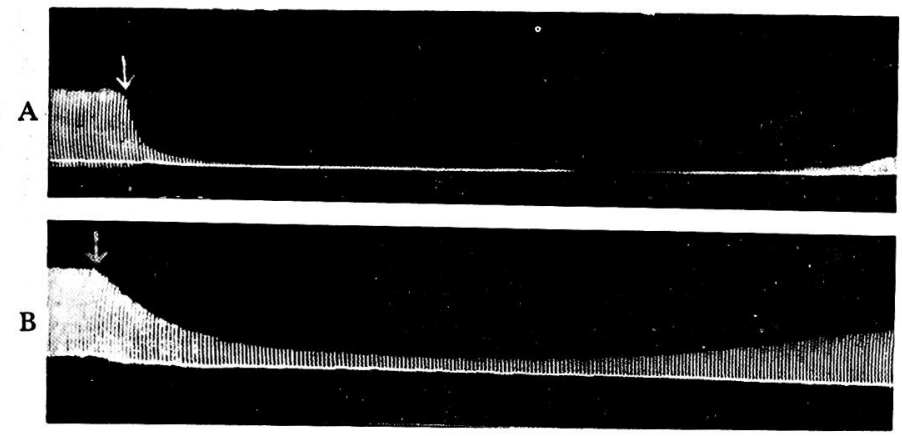

Fig. 7. Effect of whole body irradiation on $\mathrm{dTc}$ Rabbit $2.8 \mathrm{~kg}$. dTc $0.14 \mathrm{mg}$. A : Control B : after $1000 \mathrm{r}$ irradiation

Fig. 9

Fig. 8

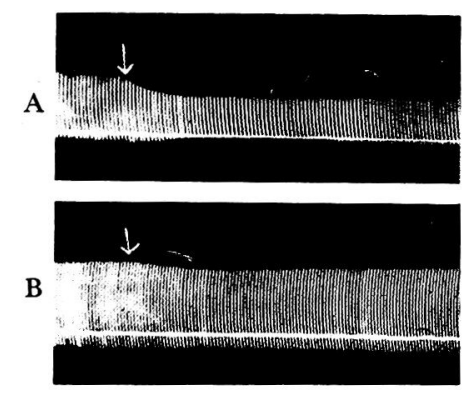

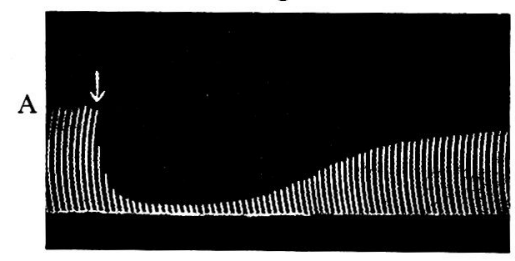

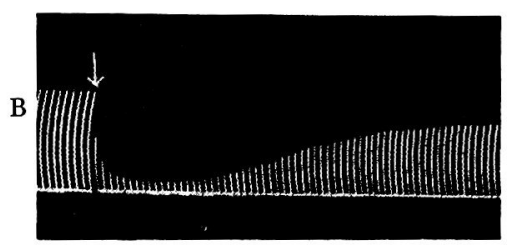

Fig. 8. Effect of liver irradiation on $d T c$ Rabbit $2.5 \mathrm{~kg}$. dTc $0.12 \mathrm{mg}$.

A : Control B : after $500 \mathrm{r}$ irradiation

Fig. 9. Effect of whole body irradiation on flaxedil Rabbit $3.0 \mathrm{~kg}$. Flaxedil $0.6 \mathrm{mg}$.

A : Control B : after $1000 \mathrm{r}$ irradiation

tion, but in cyclopropane a lowered tolerance was observed by a significant increase in the number of anesthetic deaths. Foster (1956) ${ }^{3)}$ reported a case, in which excessive respiratory depression with cyclopropane followed radiotherapy for a growth in the floor of the mouth and he suggested a possibility that irradiation around the head in appropriate dose may increase the permeability of intracranial vessels, thereby allowing entry to certain drugs (e.g. relaxants) that are usually excluded by blood brain barrier. All of them left untouched on muscle relaxants. Our experimental results revealed that the action of muscle relaxants was definitely influenced by x-ray irradiation. In rabbits the action of S.C.C. was 
potentiated and prolonged when it was given even within 1 hour after irradiation on the whole body as well as on the liver. Such a tendency was observed more remarkably and in far smaller $\mathrm{x}$-ray doses in case of liver irradiation. Covering the liver with a lead plate could minimize the effect. Irradiation on the limb concerned resulted in almost no effect, while irradiation on the head only in a slight potentiation. These facts suggest that the liver may play a great role, but a direct effect of irradiation on the local muscles or on the end-plate or a central effect due to head irradiation may be little responsible for this phenomenon. The action of dTc was rather antagonized after irradiation, while that of flaxedil was almost unaffected. In view of the mode of action of muscle relaxants a potentiating effect on S.C.C. can be possibly expected to exert an antagonizing effect on $\mathrm{dTc}$.

The mechanism of the effect of $x$-ray irradiation on muscle relaxants is beyond the scope of this study, but as mentioned above a direct effect of irradiation on the end-plate or a central effect on the nervous system could be reasonably denied. There may be a possibility that $x$-ray irradiation causes biochemical changes, particularly in cholinesterase and electrolytes. Gomi $(1955)^{5)}$ reported an inhibitory effect of x-ray irradiation on cholinesterase. In a series of deep x-ray therapy (4000-6000 r) of human uterine and breast cancer the activity of serum cholinesterase decreased, but that of red cell cholinesterase was unaffected. In rabbits both of serum and red cell cholinesterase decreased within 1-3 hours after maximal irradiation (500-1000 r). With whole body irradiation red cell cholinesterase was more remarkably depressed than serum cholinesterase, but when irradiated on the liver, the depression of serum cholinesterase was more pronounced. In his results a small dose of irradiation $(100 \mathrm{r})$ on the liver rather increased the activity of serum cholinesterase. In rabbits both of serum and red cell cholinesterase are known to be specific in nature, therefore it is questionable whether the depressed activity of cholinesterase due to $\mathrm{x}$-ray irradiation may result in a delayed decomposition of S.C.C., consequently in a potentiation and prolongation of its action. Kurisu $\left.(1956)^{6}\right)$ reported a decrease in serum potassium and an increase in serum calcium after irradiation in rabbits. Potassium deficiency is known to potentiate the action of $\mathrm{dTc}$ and calcium to antagonize both of S.C.C. and dTc. Therefore it seems difficult to explain our experimental results from the changes in electrolytes after irradiation. A review of the literatures is not enough to offer a satisfactory explanation for this experimental observation, the mechanism of which is further to be studied.

\section{SUMMARY}

The effect of $\mathrm{x}$-ray irradiation on the action of muscle relaxants was 
studied in rabbits. The muscle relaxants used were succinylcholine chloride (S.C.C.), $d$-tubocurarine chloride (dTc) and gallamine triethiodie (flaxedil). The results obtained were briefly summarized as follows:

1. The action of S.C.C. was potentiated and prolonged after x-ray irradiation on the whole body as well as on the liver. The effect was more pronounced after liver irradiation. The effect of liver irradiation was minimized by protecting the liver from $x$-ray.

2. The action of S.C.C. was slightly potentiated after x-ray irradiation on the head, but it was almost unaffected even after maximal irradiation on the limb concerned.

3. The action of dTc was rather antagonized after irradiation on the whole body or on the liver, whereas that of flaxedil was little affected.

4. A review of the literatures does not offer a satisfactory explanation for this experimental observation, but at least it can be said that instead of its direct effect on the end-plate, the effect of irradiation on the liver may play a great role in this phenomenon.

\section{References}

1) Burdick, K.H., Anesth. \& Analg., 1953, 32, 319.

2) Wilson, J.E., Anesthesiology, 1955, 16, 504.

3) Foster, P.A., Anesthesiology, 1956, 19, 735.

4) Khromov, B.M., Anesthesiology, 1958, 19, 792.

5) Gomi, M., Nippon Acta Radiologica (Jap.), 1955, 15, 17.

6) Kurisu, H., ibid., 1956, 16, 438. 